\title{
DEBIT CARDS FOR LOCAL COMMUNITY'S MONETARY TRANSACTIONS: A LITERATURE REVIEW
}

\author{
Nabilah Rozzani*, Intan Salwani Mohamed and \\ Sharifah Norzehan Syed Yusuf
}

\begin{abstract}
This conceptual paper provides a review of past studies that highlight the development of debit cards in society. A review of past literature was conducted, in which the issues were highlighted and recommendations for potential solutions for an improvement in the usage of these debit cards in a community were discussed. This paper highlights issues in the usage of debit cards for a local community. The review reveals that despite the encouraging adaptation of debit cards in the overall world economy, there are still some loopholes that need to be covered. Hence, several remedies, including intensive promotion to the public, are needed, especially if the card is being introduced as a mechanism for transactions in a particular community.
\end{abstract}

Keywords: Community; Debit Card; Technology; Payment Channel JEL classification: D11, E42, F18

\section{Introduction}

Community currency is defined as a medium to exchange goods and services within a community, in which the community is defined as a group with a common bond, such as members of a locality or an association, and that is not restricted geographically (Doteuchi, 2002). However, it is not intended that the community currency replaces the importance of national currencies, but rather to mobilise spare business capacity and stimulate the local economy by having a leverage effect on the flow of the national currency. At present, there are eleven known regions that currently have projects to operate their own community currency using debit cards (Complementary Currency Resource Center, 2013). They include Melbourne (Diamond Valley/Northern Suburbs LETS Inc.), Wörgl, Austria (LA21-Jugendprojekt I-MOTION), Leuven, Belgium (RES - Hét andere Geld!), Copenhagen, Denmark (absi), Schopfheim, Germany (GibundNimmForum), Ierapetra, Greece (PITNIO \& Time Bank of Ierapetra), Aguascalientes, Mexico (ACV/Compartienda), Christchurch, New Zealand (Time Bank), Portugal (RedeBarter - Moeda Complementar Local), Spain (Pagadoo Loyalty

\footnotetext{
*Corresponding author: Nabilah Rozzani is a Research Assistant and currently pursuing her $\mathrm{PhD}$ at the Accounting Research Institute (ARI), Universiti Teknologi MARA, 40450 Shah Alam, Selangor, Malaysia. Email: nabilah.rozzani@gmail.com.

Intan Salwani Mohamed is a Research Fellow at ARI. Email: intan838@salam.uitm.edu.my. Sharifah Norzehan Syed Yusuf is a Research Fellow at ARI. Email: shari893@ salam.uitm.edu.my.
} 
System), and also Western Franklin County Massachusetts, United States (Common Goods).

Debit cards are one of the many banking technologies that have emerged in modern society to facilitate retail payments (van der Cruijsen, Hernandez \& Jonker, 2015). These are cards that are used to make payments for transactions by the removal of funds from a certain bank account. The functional difference between a debit card and a credit card is that the removal of funds through debit cards are made immediately after the transaction, while a credit card accumulates the funds to be removed until the end of the month when the cardholder pays the bill (Mann, 2002).

Debit cards also serve as an account access device, as they are able to download value from the checking account to the accountholder's card (Wenninger \& Laster, 1995). They can then be used to initiate account-to-account transfers, which brings compatibility to an accounting system of exchange (Browne \& Cronin, 1995). According to Mann (2002), this type of card is cheaper for merchants and also has greater resistance against fraudulent transactions compared to credit cards. Debit cards have been found to be preferred among consumers as they offer speedier payment to vendors, and, hence, provide convenience to consumers who prefer buying in smaller amounts to minimise the amount of time they have to wait to complete a transaction (Klee, 2006). Also, debit cards obtain a high market share at the point of sale as their electronic fund transfer payment mechanism allows users to minimise their cash holdings from automated teller machine (ATM) withdrawals (Stix, 2004). This implies that users would no longer have to access cash through ATMs in order to purchase items (Scholnick et al., 2008).

Debit cards first entered the United States market in August 1987 as a product of its commercial bank (López \& Roberts, 2002). The next two entrants came after a short time, and, by 1996, six additional operators had entered the market. After that, there was a wave of new entrants that occurred in 1996, which was caused by regulatory changes that allowed banks to provide regular checking accounts. Today, debit cards have emerged to become the most common noncash payment instrument in terms of transactions (Runnemark, Hedman \& Xiao, 2015). This change has made it unnecessary for banks to overcome this regulatory gap, which they often did through alternative and more creative means.

In Malaysia, the usage of debit cards was only introduced in 2008, when the technology expanded to several banks, including EON Bank, Public Bank, Affin Bank, Standard Chartered, and RHB Bank (Economy Watch, 2010). Under the regulations of the Central Bank of Malaysia, anyone opening a domestic bank account and who is in possession of an ATM card is able to make payments using the card at any merchant that displays a Bankcard logo, as the ATM card doubles as a debit card (Central Bank of Malaysia, 2013). Since their introduction, the increase in debit card users in Malaysia has significantly increased, with the Central Bank of Malaysia's statistics in 2012 revealing that Malaysians spent RM5.5 billion between January and August, in which 22.9 million transactions 
were made through debit cards, as compared to RM6.3 billion being spent with 25.3 million transactions for 2011 (Noorazam, 2012).

The objective of this study is to provide a review of the issues surrounding the development of debit cards and improvements in the usage of these debit cards for a community. This is to assist and attract more users to use this technology. Hence, the review of the literature focuses mainly on the usage of debit cards. This paper is further structured as follows. Section 2 reviews previous research that has been undertaken regarding the technology of debit cards. Finally, a discussion of the findings is presented and conclusions are drawn in Section 3.

\section{Literature Review}

In this era, new technologies have been emerging as substitutes for the regular usage of currency notes. This advancement has marked a revolution in the monetary value of a nation's currency, as the community no longer needs to carry thick layers of cash and chequebooks in their pockets. With the information technologies being widely developed, financial institutions have joined in the usage of the Internet for transactions of money. This technology includes the applications of electronic fund transfers, Internet and mobile banking, credit cards and debit cards (White, 1997). Copious research has been conducted regarding the technology of debit cards, in which most examined the difference in using debit cards with other means of monetary transactions, such as credit cards and cash withdrawals through ATMs.

Rinaldi (2001), who analysed the effect of credit and debit cards, electric fund transfer-point of sale (EFT-POS) terminals and ATMs in respect of the circulation of Belgian currency, found that the number of EFT-POS terminals had a negative impact on the currency in circulation, while a weak positive effect was found for the number of payment cards. This is because consumers have no need to worry if they have any shortage of cash in their wallets, as they are guaranteed that there will be an EFT-POS terminal available to assist their purchasing transactions. The study also found that the number of ATMs placed in Belgium had a positive short-run effect on currency demand, as the availability of ATMs had improved the ease of obtaining cash. Hence, this discouraged consumers from keeping large amounts of cash in their wallets.

In the study of Stix (2004), which examined the effect of debit card usage on cash demand, it was found that the usage of debit cards significantly affected individuals' cash management, and that the average cash balances for frequent debit card users were sizably lower than those who used the card less frequently as they minimised their average purse cash holdings. This is reflected in the findings in which users who made frequent transactions with their debit card had about $12 \%$ less cash than infrequent users for the same value of cash transactions. The tendency of using cashless payment services is associated with the higher likelihood of a user obtaining a card and having lower cash balances. Other factors that promote higher card ownership include the transaction amount, private pension and ownership of bonds. This study also identified that 
individuals with high and medium education have a higher likelihood of having a debit card. To add to that, white-collar workers have a higher likelihood of debit card ownership while unemployed persons have a lower likelihood than bluecollar workers.

The findings from the study of Klee (2006) showed that more consumers chose debit cards over cheques as they expected debit card transactions to be faster than cheque transactions. Also, the study suggested that debit card users were more time sensitive than cheque users, meaning that they would prefer a faster purchase. Also, it was found in this study that users preferred debit cards to purchase in smaller amounts, which is perceived as enabling users to make more convenient purchases without the hassle of counting notes.

An experimental research was conducted by Runnemark, Hedman and Xiao (2015) to test the willingness of Copenhagen consumers to pay for a similar product using different payment channels of cash and debit card, with consideration being given to the transaction cost for the debit card. The findings from this study showed that consumers were willing to pay more using debit cards than by using cash. The researchers suggested that this situation could be caused by three factors of payment context. The first factor being the debit card's representation of money, which is similar to cash. This made consumers use a debit card in contexts where cash was not easily available to them. The second factor is the debit card's easy access to many banking technologies, which are widely growing in various sectors. Using cash might not be relevant in situations where transactions are conducted via mobile or Internet banking. Finally, the third factor is the limit for payment imposed on the debit card. A consumer might not have enough cash to purchase a product and would need to withdraw from the nearest ATM, but, as long as there is enough money on his or her debit card, the payment transaction can be completed with ease.

However, despite the many studies showing positive acceptance of the implementation of debit card technology in an overall manner, a few studies noted that the acceptance and wide usage of debit cards might be different under various circumstances that greatly affects a specific community. For example, a study by Mann (2002) showed that the acceptance of debit cards varies in different countries. He also indicated that this technology in Japan would not find as large a market as that in the United States. He argued that this is due to the different institutional factors being implemented in the two countries, in that three elements - regulatory and retail environment, communication costs, and the size of national retail economy - held the key to the success of debit card advancement in a country. It was argued that the regulatory environment would permit free participation from banks in card-based payments, while the retail environment would permit the inclusion of a substantial base of large retailers. Furthermore, low communication costs would encourage an effective anti-fraud system by enabling real-time data to be transferred between merchants and banks, while the size of the national retail economy would promote more rapid implementation of technology through its economies of scale. 
In another study, which examined the different usage of credit and debit cards, Foscht et al. (2009) showed that different categories of individuals have different preferences in the interchange usage of these two types of plastic card. According to the findings of the studies, younger people prefer debit cards, while individuals from older age groups prefer credit cards. This is due to the lack of income obtained by the younger generation, who do not necessarily have the capacity for debt payment, and, consequently, have smaller credit limits. In respect of employment, self-employed individuals prefer credit cards to debit cards. It can be assumed that self-employed men would not have a steady revenue stream, which is why they prefer credit cards to support their income in times of need; for example, while waiting for payment from consumers. Other than that, individuals who travel a lot and are accustomed to using their credit card more often are more likely to choose credit cards over debit cards.

Similarly, in the study of Abdul-Muhmin (2010), who examined how the monetary value of a retail transaction would have an impact on consumers' preferences for cash, debit and credit card payment modes, it was found that debit and credit card payment modes are less preferred for both low and high transaction values, which further suggested that electronic payment modes are clearly a substitute for cash for low transaction values, whilst credit cards act as a substitute for cash and debit cards when dealing with high transaction values. This finding was corroborated by the study of Bennett et al. (2014), who found that cash payments remain the most used retail payment instrument, and also serve as the dominant player for low-value transactions. As such, an individual's income has a significant impact on their payment preference, as individuals from a lower income group prefer cash-based transactions, while individuals from a higher income group are more comfortable using debit and credit cards.

\section{Issues and Remedies}

The current system of exchange uses cash for transactions. However, a study by van der Cruijsen, Hernandez and Jonker (2015) highlighted that debit cards are the most desired payment option among today's consumers, although they are still highly dependent on cash-based transactions. This is because cash-based transactions have become a growing habit for many consumers worldwide. The growing desirability that has recently moved towards debit card usage might help in changing consumer habits if more initiatives are made to ease the current mechanism of electronic transactions. Hence, to change this situation and start applying technology, there are a few issues that need to be looked at. These issues have been explored by previous researchers, who suggested a few ideas for developing the applicability of debit cards so that they would satisfy the twosided market of demand and supply. 


\subsection{Issues Relating to the Application of Debit Cards}

From the review of the literature, a framework and summary of current debit card implementation could be drawn to address the issues that have been highlighted by various authors. The framework is depicted in Figure 1. Through this framework, it is shown that as a customer makes a purchase from a merchant, the information stored on the customer's debit card is sent to the agent of the customer, who then sends the purchase request to the agent for the merchant.

This agent then sends a certification that reveals information concerning the merchant's payment gateway and other relevant information regarding payment to the merchant's bank. Then, the customer's agent creates the order information and payment instruction that is encrypted with the certification provided by the merchant's agent. The merchant's agent then requests authorisation from the customer's bank through its respective bank. As the request for authorisation is responded to by the customer's bank, the merchant's bank sends the authorisation approval to the merchant's agent, who prepares a purchase response and sends it to the customer's agent to complete the transaction. From this framework, it can be seen that there are two types of fee being charged on transactions involving debit cards, which are the interchange fee to the issuer of the card, and also an annual fee to the user of the card.

The interchange fee is a fee that is usually paid by merchants to issuers each time a card is used (Visa Europe, 2013), while an annual fee is a fee imposed on cardholders on a yearly basis (Hong Leong Bank, 2013). Meanwhile, for the merchants who provide the service to their customers, a discount would be provided for any transactions made to the merchants. The complexity of the current framework in the usage of debit cards has given rise to several issues that have been identified by several researchers as requiring resolution. The issues include matters involving the security features of the cards and the costs incurred by customers in debit card transactions.

In a study by Caskey \& Sellon (2005), two economic barriers that inhibit the growth of the application of debit cards were identified: the coordination issues among payment system participants and the inefficiency of pricing for the existing mechanism of payment. While the coordination issues affected merchants' incentives to apply new payment technology, the inefficient pricing affected consumers' incentives to use debit cards over other payment channels. Hence, in attracting and developing the applicability of debit cards, merchants need to find this technology cost effective as much as consumers need to find them more convenient compared to other payment instruments.

Similar issues were also highlighted by Dewan \& Chen (2005), who argued that due to the high clearing cost for merchants and complications in processing transactions, as depicted in Figure 1, merchants were only accepting debit card transactions when high density transaction volumes were deemed to make economic sense or when they were under pressure from the market. Also, the process of clearing debit card transactions by merchants was complicated, as consumers would have to be ready with at least another method of payment in case of card rejection. This was found to be inconvenient for consumers if they 
wanted to solely rely on their usage of debit cards, especially those who prefer fast-going purchases.

A recent study by Di Giulio \& Milani (2013) also found that similar issues of security and cost had been restricting Italians from taking advantage of the advancement of debit cards. This is where, as was found in the study of Jonker (2005), issues of fraud, time consumption and technical issues were the main reasons for aversion. The emergence of fraud cases relating to the usage of debit cards raises issues for consumers concerning whether or not debit cards are secure enough to allow online purchases without having the fear of having their identities stolen and money taken from their accounts for absurd reasons. In addition, these consumers were also worried that the complexity of debit card transactions would cost them more time and space for the subsequent risk of faulty cards. This would incur losses to the consumers, as they were placing their trust in the card to function properly and assist in their daily purchases.

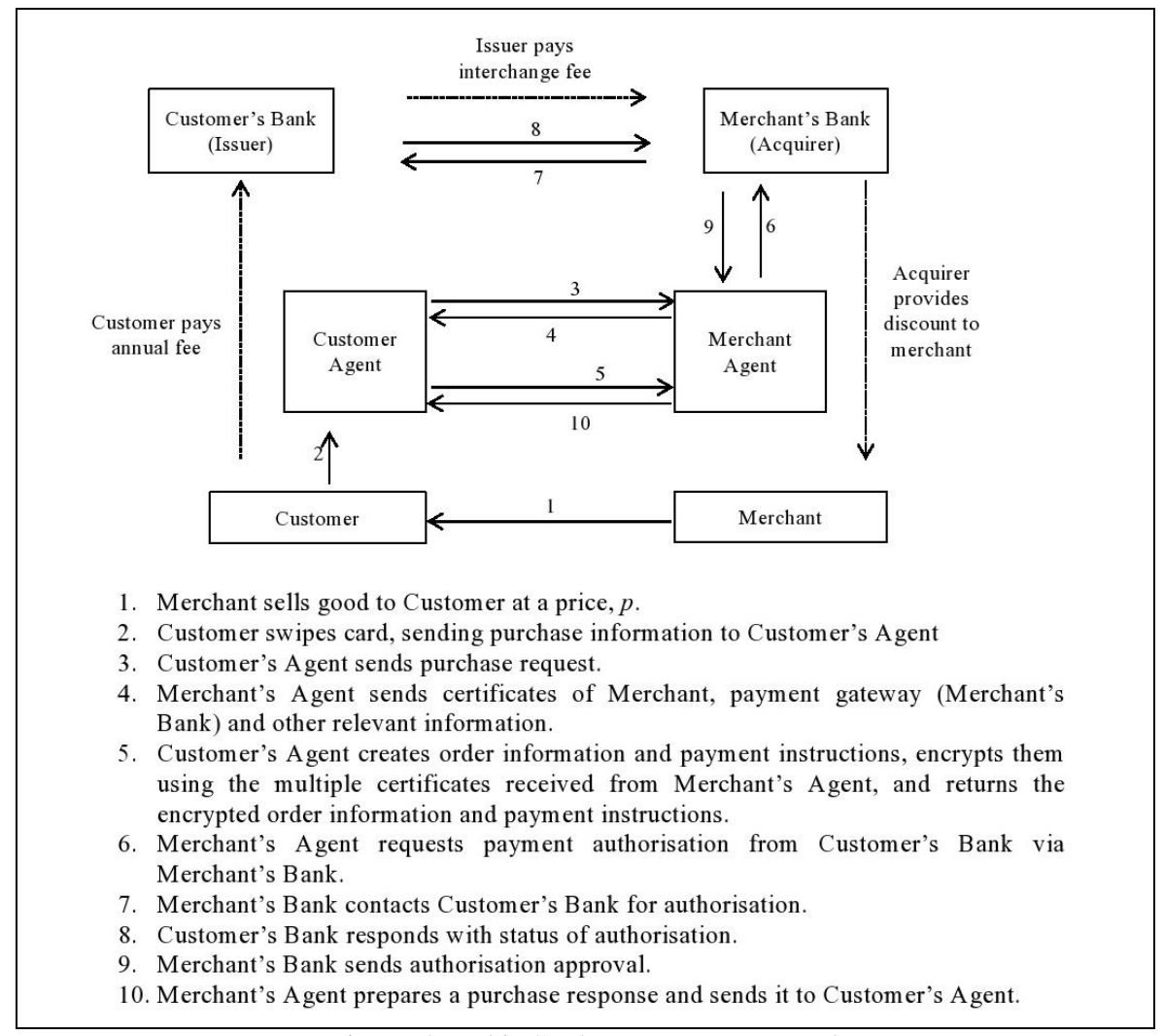

Figure 1: Debit Card Payment Framework Sources: Wright (2003); Rochet \& Tirole (2008) 
Another study by Bachas et al. (2016) on debit card usage among the poor found that the rejection of consumers from the lower income group was mainly caused by their distrust towards formal financial institutions. Combined with technological advancement, it is possible for a society to improve their members' cash management and self-control as facilitated by building trust in the financial institutions. Debit cards provide an avenue that builds consumers' trust as consumers are able to monitor their cash flow from any ATM. As their trust improves, the poor would begin to increase their savings with their respective banks in the belief that saving accounts are safer for them compared to their traditional ways of saving cash that they can physically see.

\subsection{Applying Models to Enhance the Usage of Debit Cards}

A study by Hall et al. (2001) emphasized the enhancement of a secure payment protocol to support debit card transactions through wireless networks. This is possible through the development of their Wireless Payment Protocol advancement together with the utilisation of Wireless Application Protocol's Wireless Transport Layer Security and Smart Card technology. They presumed that the introduction of this model would alter the traditional flow and reduce the processing time for transactions, and, consequently, enhance the security features of debit cards. With the introduction of this model, they contended that a reduction in the number of messages exchanged between participating agents would reduce the overall processing time of wireless payment transactions, thereby reducing the communication costs and making the transmitted data less vulnerable to malware attacks.

Through the application of a no-surcharge rule using the model proposed by Wright (2003), it was found that the model would be preferable for both the card payment system and regulators, as this model would increase the likelihood of profit and the total surplus of banks. In addition, this rule would solve the price inefficiency and high clearing cost issues, as the no-surcharge rule would prevent merchants from taking away additional surplus gained from the usage of cards. Consequently, no new alterations would be imposed to cover the membership costs, and, hence, consumers would be attracted to become cardholders, as they would only hold cards on the condition that their transactional benefits exceeded the cardholder fee issuer charges and membership fee.

To overcome the complications in processing transactions, Rochet \& Tirole (2008) attempted to manipulate the honour-all-cards rule engaged by payment card associations with merchants. This definition emphasises that merchants are required to accept all legitimate cards within a card system, irrespective of the institution issuing these cards. By this rule, service providers would integrate the separate functions of the "credit card market" and "debit card market", so that these cards could co-exist, and give the consumers the freedom of choosing whatever type of payment method they desire without having to carry an additional method of payment in their wallets. The study found that a platform may use a tie for restructuring the rates of both markets, where, in the absence of such a tie, the platform would benefit the merchants' side instead of the 
consumers' side, as consumers would have to pay more to acquire access to the multiple choice of payment.

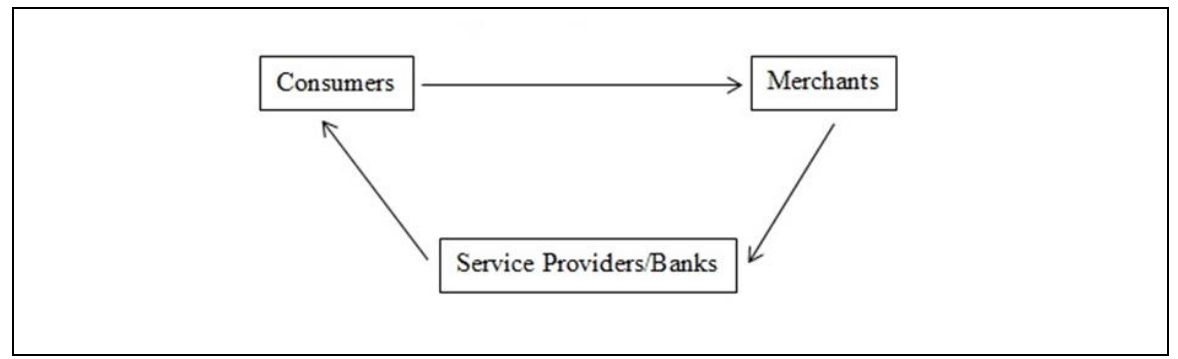

Figure 2: Proposed Framework

From the literature discussed above, it can be seen that there is a possibility for debit card enhancement that could be integrated in the environment of community currency. Hence, it is appropriate to propose a new methodology of money circulation through the usage of debit cards, which would eliminate the presence of agents in the system. The proposed framework is described in Figure 2. As depicted in Figure 2, the framework only involves the related characters, which are the consumers, merchants and service providers. By having this interrelating connection, the purpose of having a community currency is achieved. As the presence of agents is eliminated, several benefits would be made available to all parties involved. To the consumers, the annual fee for debit cards would be voided as consumers would already have acquired service charges from their respective service providers. For merchants, privileges would be available for the purchase of goods made by consumers. By circulating the cards as an idea of community currency, service providers would be serving their social corporate responsibility to the society. As the flow of monetary value would only be circulated among the participants of the society, much of the current cost of outsourcing would be reduced (Shareable, 2012).

\section{Concluding Remarks}

There are several issues that surround the implementation of debit card technology. Looking at the previous literature, the main issue that raises concern is why debit cards are only being accepted by the younger generation, not the population as a whole. This could be due to the extent that debit cards are being devised to only be reachable by younger consumers as well as security concerns.

Younger consumers are intrigued by the use of debit cards as the cards are readily available once they open a savings account. This is different to credit cards, which require cardholders to already have a source of income when applying for the cards. Also, the feature of debit cards, which only takes up the savings account balance, is a relief to the younger generation, as it is a concern in modern times that more individuals are being reported to have been declared bankrupt at a very young age. In contrast, the older generation finds it easier to 
use credit cards as they are already comfortable with the mechanism of credit cards, which give credit to their cardholders for purchasing transactions until the end of the month when the bill arrives. This means that they do not have to pay anything while using the card on an immediate basis, and only need worry about paying back their debts at the end of the month.

Looking through previous literature, it can be seen that the issues of cost, process and security were constantly highlighted in the discussions of debit card technology. Although most research only discussed in detail the problems occurring, some researchers had strived to develop models, such as the Wireless Application Protocol's Wireless Transport Layer Security and Smart Card technology; and, also the no-surcharge and honour-all-cards rules. With the introduction of these models, it is clear that there are ways to make the current situation better for all parties involved in debit card transactions. This includes the benefits to customers, merchants and service providers.

In terms of security, the microchip embedded in the debit cards could be easily removed through fluctuations in temperature, input voltage, clock rate, or point radiation source, and hit the card. In addition, the card might not have enhanced features, including tamper-resistance and encryption of critical information (Kim \& Kim, 2004). Furthermore, the terminal used to display the level of interactions with the card cannot always be trusted, especially if a personal computer is being used as the consumer-side terminal. This terminal may be compromised, in that the PIN and private key could be stolen and saved for later use.

In Malaysia, consumers are still being asked whether they would prefer to retain their ATM card or add the point-of-sale function to the card. The current study highlights the issues and benefits of debit cards to enable consumers to make better decisions that suit their lifestyle and preferences. Banks could also benefit from the current study in an effort to promote the better usage of debit cards among consumers. Having the convenience of automatically coupling point-of sale and ATM capabilities on a single card is indeed an intriguing possibility, which would attract consumers to shift to debit card usage. The features of debit cards in general are able to provide convenience for consumers, as they would only need to carry a single multipurpose card. The current study also adds important discussions concerning the benefits and disadvantages of debit card usage in today's business transactions from both the commercial and corporate point of view.

If we are able to expand the application of debit cards in daily consumer transactions, their growth would slowly replace the traditional consumer payment instruments of cash and cheques, hence resulting in a significant change in consumer payment patterns. If this situation becomes a reality, banks would also reap benefits concerning the move of their non-credit taking cardholders towards debit card transactions, as their costs would be even further reduced (Worthington, 1995). 


\section{Acknowledgements}

The authors would like to thank the Accounting Research Institute and the Ministry of Higher Education for the research grant provided to conduct this research.

\section{References}

Abdul-Muhmin, A. G. (2010). Transaction size effects on consumers' retail payment mode choice. International Journal of Retail \& Distribution Management, 38(6), 460-478.

Bennett, B., Conover, D., O’Brien, S., \& Advincula, R. (2014). Cash continues to play a key role in consumer spending: Evidence from the diary of consumer payment choice. San Francisco: Board of Governors of the Federal Reserve System.

Browne, F. X., \& Cronin, D. (1997). Payment technologies, financial innovation, and Laissez-Faire banking: A further discussion of the issues. In: Dorn, J.A. The Future of Money in the Information Age. Washington: Cato Institute, 15-20.

Bachas, P., Gertler, P., Higgins, S., \& Seira, E. (2016). Banking on trust: How debit cards help the poor to save more. Connecticut: Yale University. NBER Working Paper No. 22463.

Caskey, J. P., \& Sellon, G. H. (2005). Is the Debit Card Revolution Finally Here?. Economic Review: Federal Reserve Bank of Kansas City, 79(4), 79-95.

Central Bank of Malaysia (2013). Payment Systems in Malaysia, http://www.bnm.gov.my/index.php?ch=ps_mps\&pg=ps_mps_type\&lang=e $n \& z=1 \#$ Debit, accessed $7^{\text {th }}$ January 2015.

Complementary Currency Resource Center (2013). Online database of complementary currencies worldwide: Public area, http://www.complementarycurrency.org/ccDatabase/, accessed $7^{\text {th }}$ January 2015.

Dewan, S. G. \& Chen, L. (2005). Mobile payment adoption in the US: A crossindustry cross-platform solution. Journal of Information Privacy \& Security, $1-26$.

Di Giulio, D., \& Milani, C. (2013). Plastic money diffusion and usage: An empirical analysis on Italian households. Economic Notes, 42(1), 47-74.

Doteuchi, A. (2002). Community currency and NPOs - A model for solving social issues in the 21st century. NLI Research, 163, 1-11.

Economy Watch. (2010). Malaysia Debit Card, Consumer Base Expanding, http://www.economywatch.com/debit-card/international/Malaysia-DebitCard.html, accessed $7^{\text {th }}$ January 2015.

Foscht, T., Maloles, C., Swoboda, B., \& Chia, S. (2009). Debit and credit card usage and satisfaction: Who uses which and why - Evidence from Austria. International Journal of Bank Marketing, 28(2), 150-165.

Hall, J., Kilbank, S., Barbeau, M., \& Kranakis, E. (2001). WPP: A secure payment protocol for supporting credit- and debit-card transactions over 
wireless networks. Proceedings of the IEEE International Conference on Telecommunications (ICT), June, Bucharest.

Hong Leong Bank (2013). Hong Leong Debit Card Terms and Conditions, http://www.hlb.com.my/pfs/dep/debitcard_TC.pdf, accessed $17^{\text {th }}$ November 2014.

Jonker, N. (2005). Payment instruments as perceived by consumers - A public survey. Netherlands: Netherlands Central Bank. DNB No. 053.

Kim, W., \& Kim, H. (2004). Smart cards: Status, issues, and US adoption. Journal of Object Technology 3(5), 25-30.

Klee, E. (2006). Paper or plastic? The effect of time on check and debit card use at grocery stores. Washington D.C.: Board of Governors of the Federal Reserve System.

López, L. E., \& Roberts, E. B. (2002). First-mover advantages in regimes of weak appropriability: The case of financial services innovations. Journal of Business Research, 55, 997-1005.

Mann, R. J. (2002). Credit Cards and Debit Cards in the United States and Japan. Michigan: John M. Olin Center for Law \& Economics, University of Michigan.

Noorazam, N. (2012, October). Malaysia's debit card revolution. New Straits Times.

Rinaldi, L. (2001). Payment Cards and Money Demand in Belgium. Belgium: KULeuven. CES Discussion Paper DPS 01.16

Rochet, J. C., \& Tirole, J. (2008). Tying in two-sided markets and the honor all cards rule. International Journal of Industrial Organization, 26, 1333-1347.

Runnemark, E., Hedman, J., \& Xiao, X. (2015). Do consumers pay more using debit cards than cash?. Electronic Commerce Research and Applications, 14(5), 285-291.

Scholnick, B., Massoud, N., Saunders, A., Carbo-Valverde, S., \& RodríguezFernández, F. (2008). The economics of credit cards, debit cards and ATMs: A survey and some new evidence. Journal of Banking \& Finance, 32, 14681483.

Shareable. (2012). How to Start a Community Currency. http://www.shareable.net/blog/how-to-start-a-community-currency, accessed $9^{\text {th }}$ January 2015.

Stix, H. (2004). How do debit cards affect cash demand? Survey data evidence. Empirica 31, 93-115.

van der Cruijsen, C., Hernandez, L., \& Jonker, N. (2015). In love with the debit card but still married to cash. Amsterdam: De Nederlandsche Bank NV. DNB Working Paper No. 461.

Visa Europe. (2013). Our fees. http://www.visaeurope.com/en/about_us/our_business/fees_and_interchang e.aspx, accessed 17th June 2013.

Wenninger, J., \& Laster, D. (1995). The electronic purse. Current Issues in Economics and Finance, 1(1), 1-5. 
White, L.H. (1997). The technology revolution and monetary evolution. In: Dorn, J.A. The Future of Money in the Information Age. Washington: Cato Institute, 15-20.

Worthington, S. (1995). The cashless society. International Journal of Retail and Distribution Management, 23, 31-41.

Wright, J. (2003). Optimal card payment systems. European Economic Review, 47, 587-612. 